\title{
Transcatheter mitral repair according to the cause of mitral regurgitation: Real-life data from the Spanish MitraClip registry
}

\author{
Isaac Pascual, ${ }^{\mathrm{a}, \mathrm{b}, \mathrm{c}}$ Dabit Arzamendi, ${ }^{\mathrm{d}}$ Fernando Carrasco-Chinchilla, ${ }^{\mathrm{e}}$ Felipe Fernández-Vázquez, ${ }^{\mathrm{f}}$ \\ Xavier Freixa, ${ }^{\mathrm{g}}$ Luis Nombela-Franco, ${ }^{\mathrm{h}}$ Pablo Avanzas, ${ }^{\mathrm{a}, \mathrm{b}, \mathrm{c}, *}$ Ana María Serrador Frutos, ${ }^{\mathrm{i}}$ Manuel Pan, ${ }^{\mathrm{j}}$ \\ Ana Belén Cid Álvarez, ${ }^{\mathrm{k}}$ Rosa Ana Hernández-Antolín, ${ }^{1}$ Leire Andraka Ikazuriaga, ${ }^{\mathrm{m}}$ \\ Ignacio Cruz-González, ${ }^{\mathrm{n}}$ José Luis Díez Gil, ${ }^{\circ}$ María Soledad Alcasena Juango, ${ }^{\mathrm{p}}$ Alberto Berenguer Jofresa, ${ }^{\mathrm{q}}$ \\ Juan H. Alonso-Briales, ${ }^{\mathrm{e}}$ Chi Hion Li, ${ }^{\mathrm{d}}$ Tomás Benito González, ${ }^{\mathrm{f}}$ Ander Regueiro, ${ }^{\mathrm{g}}$ Germán Armijo, ${ }^{\mathrm{h}}$ \\ Víctor León, ${ }^{\mathrm{a}, \mathrm{b}}$ Ignacio J. Amat-Santos, ${ }^{\mathrm{i}}$ Miguel Romero, ${ }^{\mathrm{j}}$ Ramiro Trillo Nouche, ${ }^{\mathrm{k}}$ \\ Covadonga Fernández-Golfinn, ${ }^{1}$ Lara Ruiz Gómez, ${ }^{\mathrm{m}}$ Rafael Campos-Arjona, ${ }^{\mathrm{e}}$ Xavier Millán, ${ }^{\mathrm{d}}$ \\ Carmen Garrote Coloma, ${ }^{\mathrm{f}}$ Laura Sanchis, ${ }^{\mathrm{g}}$ Pilar Jiménez-Quevedo, ${ }^{\mathrm{h}}$ César Morís, ${ }^{\mathrm{a}, \mathrm{b}, \mathrm{c}}$
} José María Hernández-García, ${ }^{\mathrm{e}}$ Antonio Serra, ${ }^{\mathrm{d}}$ Armando Pérez de Prado, ${ }^{\mathrm{f}}$ and Rodrigo Estévez-Loureiror

a Área del Corazón, Hospital Universitario Central de Asturias, Oviedo, Asturias, Spain

${ }^{\mathrm{b}}$ Instituto de Investigación Sanitaria del Principado de Asturias, Oviedo, Asturias, Spain

'Departamento de Biología Funcional, Universidad de Oviedo, Oviedo, Asturias, Spain

d Servicio de Cardiología, Hospital de la Santa Creu i Sant Pau, Barcelona, Spain

e Servicio de Cardiología, Hospital Clínico Universitario Virgen de la Victoria, Málaga, Spain

${ }^{\mathrm{f}}$ Servicio de Cardiología, Complejo Hospitalario de León, León, Spain

${ }^{\mathrm{g}}$ Servicio de Cardiología, Institut Clínic Cardiovascular, Hospital Clínic de Barcelona, Barcelona, Spain

${ }^{\mathrm{h}}$ Instituto Cardiovascular, Hospital Clínico San Carlos, Madrid, Spain

i Instituto de Ciencias del Corazón, Hospital Clínico Universitario de Valladolid, Valladolid, Spain

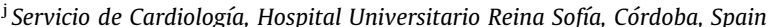

${ }^{\mathrm{k}}$ Servicio de Cardiología, Complejo Hospitalario Universitario Santiago de Compostela, CIBERCV, Santiago de Compostela, A Coruña, Spain

${ }^{1}$ Servicio de Cardiología, Hospital Universitario Ramón y Cajal, Madrid, Spain

${ }^{\mathrm{m}}$ Servicio de Cardiología, Hospital Universitario de Basurto, Bilbao, Vizcaya, Spain

${ }^{\mathrm{n}}$ Servicio de Cardiología, Hospital Universitario de Salamanca, Salamanca, Spain

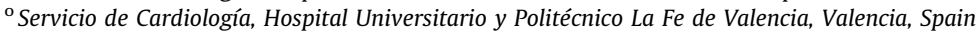

PÁrea Clínica del Corazón, Complejo Hospitalario de Navarra, Pamplona, Navarra, Spain

${ }^{\mathrm{q}}$ Servicio de Cardiología, Hospital General de Valencia, Valencia, Spain

${ }^{\mathrm{r}}$ Área de Cardiología, Complejo Hospitalario Universitario de Vigo, Vigo, Pontevedra, Spain

Article history:

Received 27 April 2019

Accepted 19 July 2019

\section{Keywords:}

MitraClip

Transcatheter mitral valve repair

Severe mitral regurgitation

Etiology

\begin{abstract}
A B S T R A C T
Introduction and objectives: Transcatheter mitral valve repair (TMVR) with MitraClip is a therapeutic option for high surgical risk patients with severe mitral regurgitation (MR). The main objective of this study was to analyze differences in outcomes in patients with severe MR according to the cause of MR. Methods: Observational, multicenter, and prospective study with consecutive patient inclusion. The primary endpoint was the combination of all-cause mortality and new readmissions due to heart failure after 1 year. We compared clinical and procedural characteristics and the event rate for each MR group. We performed a multivariate analysis to identify predictive variables for the primary endpoint.

Results: A total of 558 patients were included: 364 (65.2\%) with functional etiology, 111 (19.9\%) degenerative and 83 (14.9\%) mixed. The mean age was $72.8 \pm 11.1$ years and $70.3 \%$ of the sample were men. There were 95 (17\%) events in the overall sample. No significant differences were found in the 3 groups in the number of primary outcome events: 11 (11.3\%) in degenerative MR, $71(21.3 \%)$ in functional MR, and $13(18.1 \%)$ in mixed MR $(P=.101)$. Independent predictors were functional class $(P=.029)$, previous surgical revascularization $(P=.031)$, EuroSCORE II $(P=.003)$, diabetes mellitus $(P=.037)$, and left ventricular ejection fraction $(P=.015)$.

Conclusions: This study confirms the safety and efficacy of TMVR with MitraClip irrespective of MR etiology in real-life data and shows the main factors related to prognosis during the first year of follow up.
\end{abstract}

(c) 2019 Sociedad Española de Cardiología. Published by Elsevier España, S.L.U. All rights reserved.

\footnotetext{
* Corresponding author: Área del Corazón, Hospital Universitario Central de Asturias, Avda. de Roma s/n, 33011 Oviedo, Asturias, Spain.

E-mail address: avanzas@gmail.com (P. Avanzas).
} 
Reparación mitral transcatéter según la etiología de la insuficiencia mitral: datos en vida real procedentes del registro español de MitraClip

Palabras clave:

MitraClip

Reparación de la válvula mitral transcatéter Insuficiencia mitral grave

Etiología
R E S U M E N

Introducción y objetivos: La reparación de la válvula mitral transcatéter (RVMT) con el sistema MitraClip es un tratamiento para los pacientes con insuficiencia mitral (IM) grave de alto riesgo quirúrgico. El objetivo principal fue analizar los resultados del RVMT en pacientes con IM grave, según la etiología. Métodos: Estudio observacional, prospectivo y multicéntrico con inclusión de pacientes consecutivos. El objetivo primario fue el combinado de mortalidad por todas las causas y reingresos hospitalarios por insuficiencia cardiaca al año. Se compararon las características clínicas y del procedimiento y los eventos para cada grupo de IM. Se realizó un análisis multivariable para determinar las variables asociadas con el objetivo primario.

Resultados: Se incluyó a 558 pacientes; 364 (65,2\%) tenían etiología funcional; 111 (19,9\%), degenerativa, y 83 (14,9\%), mixta. La media de edad fue $72,8 \pm 11,1$ años y eran varones el $70,3 \%$. Respecto al objetivo primario, hubo 95 (17\%) eventos en toda la serie. No hubo diferencias significativas entre los 3 grupos en el número de eventos del objetivo primario: $11(11,3 \%)$ en la IM degenerativa, $71(21,3 \%)$ en la funcional y $13(18,1 \%)$ en la mixta $(p=0,101)$. Los predictores independientes fueron la clase funcional $(p=0,029)$, la revascularización quirúrgica previa $(p=0,031)$, el EuroSCORE II $(p=0,003)$, la diabetes mellitus $(p=0,037)$ y la fracción de eyección del ventrículo izquierdo $(p=0,015)$.

Conclusiones: Este trabajo confirma con datos de la práctica clínica la seguridad y la eficacia de la RVMT independientemente de la etiología de la IM y se documentan los principales factores asociados con el pronóstico durante el primer año de seguimiento.

๔ 2019 Sociedad Española de Cardiología. Publicado por Elsevier España, S.L.U. Todos los derechos reservados.

\begin{abstract}
Abbreviations
DMR: degenerative mitral regurgitation

FMR: functional mitral regurgitation

HF: heart failure

MMR: mixed mitral regurgitation

MR: mitral regurgitation

TMVR: transcatheter mitral valve repair
\end{abstract}

\section{INTRODUCTION}

Mitral regurgitation (MR) is a valve disease with increasing prevalence. Severe MR is associated with progressive left ventricular dilatation and the development of heart failure (HF). Untreated symptomatic patients have annual mortality rates exceeding $5 \%^{1,2}$ MR interventions vary according to the pathophysiological mechanism: in primary or organic MR, some of the components of the mitral apparatus (leaflets, chordae, or papillary muscles) are affected and valve repair/replacement is recommended when there are symptoms, ventricular dilatation, pulmonary hypertension, or atrial fibrillation. ${ }^{3,4}$ In secondary $\mathrm{MR}$, the components of the mitral apparatus are intact but leaflet coaptation fails due to ventricular or ring dilatation. These patients usually have ventricular dysfunction, and most receive medical therapy. Surgical treatment is only considered when concomitant coronary revascularization is required. ${ }^{3-5}$

The emergence of transcatheter mitral valve repair (TMVR) techniques has bolstered the therapeutic arsenal for the treatment of severe MR. The MitraClip system (Abbott; Menlo Park, California, United States) is an increasingly widespread therapeutic option for severe MR patients who are at high surgical risk or are inoperable. ${ }^{4,5}$ The management of patients with severe MR of degenerative origin with TMVR with the MitraClip is safe and effective. ${ }^{6}$ The approach achieves good clinical outcomes, with a reduction in MR severity that is slightly lower in the long-term vs that achieved by surgical treatment, but shows greater safety and improved functional class and quality of life. , $^{7}$

Although the initial MitraClip evidence was obtained in the field of degenerative MR (DMR), most patients treated in international registries had functional MR (FMR). In this population, an improved functional class was observed in more than $75 \%$ of patients. $^{9-12}$ This led to the comparison of TMVR plus optimal medical therapy vs optimal medical therapy alone in 2 randomized studies. While in one of them (COAPT), the TMVR plus optimal medical therapy group showed significantly reduced mortality and readmissions for $\mathrm{HF}$, the other (MITRA-FR) found no significant differences. $^{13,14}$

Thus, the main objective of this study was to analyze the differences in 1-year all-cause mortality and hospital readmissions for $\mathrm{HF}$ in patients with degenerative, functional, and mixed MR managed with TMVR with the MitraClip system.

\section{METHODS}

\section{Study design and population}

In this observational and multicenter study, data were obtained from the Spanish MitraClip registry. This registry is endorsed by the Cardiac Catheterization and Interventional Cardiology (SHCI) Section of the Spanish Society of Cardiology and has prospectively included consecutive patients treated with MitraClip since June 1, 2012. The inclusion of patients treated with the MitraClip in the Spanish registry is open to all members of the SHCI who perform the technique. This study analyzed the data of the patients included until July 1,2018 , from 16 Spanish hospitals. The indication for TMVR with MitraClip was established as the best therapeutic option after evaluation of each patient by the multidisciplinary team (Heart Team) of each center. 
For the purpose of the study, 3 groups were defined according to MR cause (3,4 $^{3}$ primary MR or DMR, which entails a direct and structural involvement of some of the components of the mitral apparatus; secondary MR or FMR, which shows structurally normal leaflets and chordae but an imbalance between the closing and tethering forces in the valve, secondary to alterations in left ventricular geometry; and finally, mixed MR (MMR), whose etiological mechanism is mainly functional, but there is leaflet degeneration that could have implications for percutaneous repair.

A specialized centralized database was designed for the prospective and consecutive inclusion of all of the patients' demographic, echocardiographic, procedural, and follow-up variables.

All included patients signed an informed consent form.

\section{Description of the procedure and device}

The MitraClip device is a percutaneous treatment system for MR that is based on the surgical technique proposed by Alfieri. ${ }^{6,7}$ The system consists of a cobalt-chromium clip with 2 arms and 2 grippers that are used to trap both mitral leaflets to create a double orifice valve. The device is transseptally introduced and, under echocardiographic and fluoroscopic visualization, its delivery system is advanced until it is placed at the site of maximum regurgitation. The use of real-time 3-dimensional transesophageal echocardiography is essential to guide the procedure and also makes it possible to attempt the treatment of morphologically complex valves. Once transesophageal echocardiography has confirmed that both leaflets have been introduced into the arms of the system, the device can be closed and the result of the MR reduction can be checked by transesophageal echocardiography. If the result is acceptable, the clip can be released; if not, it can be reopened and relocated for another attempt. The implantation is performed in the catheterization laboratory under general anesthesia to obtain an adequate image of the mitral valve and properly capture the leaflets in the device. ${ }^{6,7}$

\section{Definition of the variables}

Procedural success was defined as the correct implantation of at least 1 clip and MR reduction to a grade less than or equal to moderate $(2+)$. Procedural time was defined as the duration from anesthetic induction to the end of the procedure. Device implantation time was calculated from the insertion of the release system until its removal. Procedure-related bleeding and its severity were defined according to the criteria of the Bleeding Academic Research Consortium (BARC). ${ }^{15}$ Functional class was defined according to the classification of the New York Heart Association (NYHA).

Percutaneous mitral repair was defined as urgent when it was performed during patient admission for acute HF and clinical instability, either due to recurrent acute lung edema episodes requiring intravenous medication or due to the development of cardiogenic shock.

MR severity, both at diagnosis and in the evaluation after the procedure and during follow-up, was determined according to the recommendations of the European Society of Cardiology. 4,16

\section{Study endpoints}

The primary study endpoint was a composite of all-cause mortality and readmission for HF during the first year of follow-up.
The secondary objectives were post-TMVR analysis of functional class and MR severity according to its cause.

\section{Statistical analysis}

In the descriptive analysis, absolute (No.) and relative (\%) frequencies were calculated for qualitative variables. For quantitative variables, the normality of the variables was assessed with the Kolmogorov-Smirnov goodness-of-fit test; variables are expressed as mean \pm standard deviation if normally distributed and as median [interquartile range] if not. To address the study endpoints, analyses were performed to compare the 3 MR types (DMR, FMR, and MMR). The differences among these groups in the qualitative variables were calculated as a percentage difference with the Pearson chi-square test; if $20 \%$ or more of cells had expected frequencies $<5$, likelihood ratio correction was performed. Comparisons among the 3 groups for continuous quantitative variables were analyzed by one-way ANOVA, with post hoc analysis of multiple Bonferroni comparisons or with the Kruskal-Wallis test according to the distribution of the variable.

The nonparametric Kaplan-Meier survival estimator was used to determine the time to all-cause mortality during 12 months of follow-up, as well as readmissions for HF and the composite of mortality and readmissions. In conjunction with the log-rank test, the median survival and the survival curves were used to compare the event-free survival rates among the groups according to MR cause.

Finally, independent predictors of the primary study endpoint were analyzed by Cox proportional hazards regression; hazard ratios (HRs) with 95\% confidence intervals (95\%CIs) were calculated for all patients, with adjustment for age, sex, type of $\mathrm{MR}$, and the variables with $P<.1$ in the univariate analysis, using a stepwise forward model. A 95\% level of significance was applied in the statistical tests $(P<.05)$.

For data analysis, the SPSS version 23.0 statistical package was used (IBM Corp.; Armonk, New York, United States).

\section{RESULTS}

\section{Baseline characteristics of the population}

In total, 558 patients were included: 364 had FMR (65.2\%), 111 had DMR (19.9\%), and 83 had MMR (14.9\%). Baseline characteristics are shown in table 1 . The mean age was $72.8 \pm 11.1$ years and men comprised $70.3 \%$. Compared with patients with FMR, patients with DMR were older, were more likely to have had prior cardiac surgery, and had higher surgical risk. Among patients with FMR and MMR, there were higher proportions of men, previous ischemic heart disease, percutaneous revascularization, and previous surgery and worse ejection fraction.

\section{Procedure}

Procedural characteristics are shown in table 2 . The procedure was successful in $93 \%$ of patients, without significant differences according to MR cause. There were also no significant differences in procedure duration, although the procedures were longer in the FMR group, or in the number of clips implanted. In $5 \%$ of the patients, the indication for TMVR was urgent, without significant differences according to type of MR.

Procedural and in-hospital complications are shown in table 3. Procedure-related pericardial effusion was observed in 13 patients, 4 with DMR, 8 with FMR, and 1 with MMR. Of these, 4 patients required pericardiocentesis ( 2 with DMR and 
Table 1

Baseline characteristics of the sample

\begin{tabular}{|c|c|c|c|c|c|}
\hline & Total $(n=558)$ & $\operatorname{DMR}(\mathrm{n}=111)$ & FMR $(n=364)$ & MMR $(n=83)$ & $P$ \\
\hline Age, $y$ & $72.8 \pm 11.1$ & $79.2 \pm 8.2$ & $70.2 \pm 11.3$ & $75.4 \pm 9.5$ & $<.001$ \\
\hline Sex & & & & & $<.001$ \\
\hline Men & $392(70.3)$ & $61(55.0)$ & $278(76.4)$ & $53(63.9)$ & \\
\hline Women & $166(29.7)$ & $50(45.0)$ & $86(23.6)$ & $30(36.1)$ & \\
\hline Weight, kg & $74.2 \pm 15.3$ & $71.5 \pm 15.7$ & $75.0 \pm 15.5$ & $74.2 \pm 13.5$ & .113 \\
\hline BMI & $27.1 \pm 4.7$ & $27.2 \pm 5.4$ & $27.0 \pm 4.4$ & $27.8 \pm 4.8$ & .381 \\
\hline$B M I \geq 30$ & $134(24.0)$ & $33(29.7)$ & $78(21.4)$ & $23(27.7)$ & .139 \\
\hline Previous cardiac surgery & $108(19.4)$ & $22(19.8)$ & $61(16.8)$ & $25(30.1)$ & .028 \\
\hline NYHA functional class & & & & & .662 \\
\hline II & $64(11.5)$ & $11(9.9)$ & $45(1.4)$ & $8(9.6)$ & \\
\hline III & $382(68.5)$ & $77(69.4)$ & $251(69.0)$ & $54(65.1)$ & \\
\hline IV & $112(20.1)$ & $23(20.7)$ & $68(18.7)$ & $21(25.3)$ & \\
\hline Mitral annuloplasty & $10(1.8)$ & $2(1.8)$ & $8(2.2)$ & 0 & .19 \\
\hline Aortic surgery & $27(4.8)$ & $7(6.3)$ & $13(3.6)$ & $7(8.7)$ & .128 \\
\hline Ischemic heart disease & $303(54.3)$ & $37(33.3)$ & $211(58.0)$ & $55(66.3)$ & $<.001$ \\
\hline Recent myocardial infarction $(<90 \mathrm{~d})$ & $33(5.9)$ & $1(0.9)$ & $26(7.1)$ & $6(7.2)$ & .044 \\
\hline Surgical revascularization & $97(17.4)$ & $13(11.7)$ & $68(18.7)$ & $16(19.3)$ & .21 \\
\hline TAVI & $20(3.6)$ & $7(6.3)$ & $8(2.2)$ & $5(6.0)$ & .064 \\
\hline Percutaneous revascularization & $208(37.3)$ & $18(16.2)$ & $156(42.9)$ & $34(41.0)$ & $<.001$ \\
\hline EUROSCORE II, \% & $4.8(2.7-9.5)$ & $5.3(3.5-9.0)$ & $4.4(2.4-8.7)$ & $7.0(3.3-13.8)$ & .001 \\
\hline STS score & $4.0[1.8-6.9]$ & $4.7[2.4-7.5]$ & $3.3[1.5-6.5]$ & $4.7[3.2-8.1]$ & .006 \\
\hline COPD & $124(22.2)$ & $34(30.6)$ & $72(19.7)$ & $18(21.7)$ & .053 \\
\hline Stroke & $47(8.4)$ & $8(7.2)$ & $32(8.8)$ & $7(8.4)$ & .874 \\
\hline Severe pulmonary hypertension ( $\geq 60 \mathrm{mmHg}$ ) & $143(25.6)$ & $32(28.8)$ & $85(23.3)$ & $26(31.3)$ & .216 \\
\hline Type 2 diabetes mellitus & $194(34.7)$ & $31(27.9)$ & $132(36.2)$ & $31(37.3)$ & .241 \\
\hline Hypertension & $399(71.4)$ & $83(74.8)$ & $249(68.2)$ & $67(80.7)$ & .051 \\
\hline Smoker & $129(23.1)$ & $19(17.1)$ & $90(24.7)$ & $20(24.1)$ & .249 \\
\hline Dyslipidemia & $311(55.6)$ & $55(49.5)$ & $200(54.8)$ & $56(67.5)$ & .039 \\
\hline Renal failure (creatinine $>2.5 \mathrm{~g} / \mathrm{dL}$ ) & $27(5.2)$ & $6(5.7)$ & $15(4.4)$ & $6(7.7)$ & .488 \\
\hline Atrial fibrillation & $323(57.8)$ & $77(69.4)$ & $199(54.5)$ & $47(56.6)$ & .021 \\
\hline LVEF $<30 \%$ & $142(25.4)$ & $3(2.7)$ & $131(36.0)$ & $8(9.6)$ & $<.001$ \\
\hline LVEF, \% & $40.0 \pm 14.9$ & $57.1 \pm 13.0$ & $34.2 \pm 11.4$ & $42.4 \pm 12.3$ & $<.001$ \\
\hline Hemodialysis & $15(2.7)$ & $4(3.6)$ & $8(2.2)$ & $3(3.6)$ & .627 \\
\hline
\end{tabular}

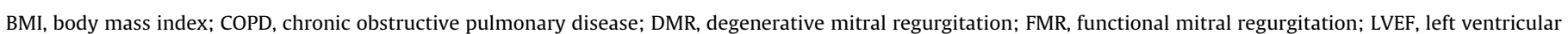

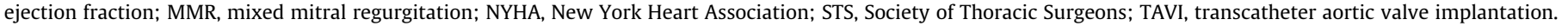
Values represent No. (\%), mean \pm standard deviation, mean (range), or median [interquartile range].

2 with FMR). Only 1 patient in the FMR group required surgical treatment for pericardial effusion. There was clinically significant bleeding (BARC 3a or 3b) in 3.1\% (9 patients). In-hospital mortality was $2.5 \%$ (14 patients) and was significantly higher in the FMR and MMR groups than in the DMR group (3\% and 3.6\% vs $0 \% ; P=.041)$.

There were 14 in-hospital deaths: 11 patients had FMR and 3 had MMR. The causes of the in-hospital mortality in the FMR group were as follows: 7 due to refractory HF, 2 due to sepsis ( 1 of urinary origin and another of respiratory origin), 1 stroke, and 1 multiorgan failure. In the MMR group, the causes were refractory $\mathrm{HF}$ in 2 and respiratory failure in 1 . There were no in-hospital deaths in the DMR group.

\section{Primary endpoint}

At 12 months of follow-up, the total number of events of the primary study endpoint was $95(18.9 \%)$ in the entire series: 11 in the DMR group (11.3\%), 71 in the FMR group (21.3\%), and 13 in the MMR group (18.1\%), with no significant differences among the 3 groups $(P=.101)$. All-cause mortality in the entire series at 12 months of follow-up was $14 \%$ (78 patients), distributed according to MR type as follows: 13 patients in the DMR group (11.7\%), 57 in the FMR group (15.7\%), and 8 in the MMR group $(9.6 \%)$, with no significant differences among the 3 groups $(P=.728)$. The percentage of readmissions for HF in the entire series at 12 months was $18 \%$ (101 patients): 13 in the DMR group (11.7\%), 77 in the FMR group (21.2\%), and 11 in the MMR group (13.3\%); the rate was significantly higher in the FMR group $(P=.047)$. Figure 1 shows the 12 -month survival curves for the composite endpoint (figure $1 \mathrm{~A}$ ), all-cause mortality (figure 1B), and readmissions for $\mathrm{HF}$ (figure $1 \mathrm{C}$ ), according to MR cause.

Univariate and multivariate analyses of the composite endpoint at 12 months are shown in table 4 and table 5, respectively. The variables associated with the primary endpoint were functional class $(P=.029)$, previous surgical revascularization $(P=.031)$, the EuroSCORE II $(P=.003)$, diabetes mellitus $(P=.037)$, and left 
Table 2

Procedural characteristics

\begin{tabular}{|c|c|c|c|c|c|}
\hline & Total $(n=558)$ & $\operatorname{DMR}(\mathrm{n}=111)$ & FMR $(n=364)$ & $\operatorname{MMR}(\mathrm{n}=83)$ & $P$ \\
\hline Procedural success & $524(93.9)$ & $108(96.4)$ & $337(92.6)$ & $80(96.4)$ & .201 \\
\hline Number of clips implanted & $1.54 \pm 0.67$ & $1.64 \pm 0.71$ & $1.53 \pm 0.68$ & $1.46 \pm 0.59$ & .175 \\
\hline Procedural duration, min & $135(107-183)$ & $131(119-204)$ & $139(106-185)$ & $120(102-163)$ & .144 \\
\hline Implantation time, min & $80(60-105)$ & $80(60-100)$ & $90(60-120)$ & $60(50-92)$ & .012 \\
\hline Degree of mitral regurgitation before the clip & & & & & .018 \\
\hline III & $130(23.3)$ & $15(13.5)$ & $91(25.0)$ & $24(28.9)$ & \\
\hline IV & $428(76.7)$ & $96(86.5)$ & $273(75.0)$ & $59(71.1)$ & \\
\hline Degree of mitral regurgitation after the clip & & & & & .120 \\
\hline 0 & $24(4.5)$ & $5(4.7)$ & $16(4.5)$ & $3(3.8)$ & \\
\hline I & $300(55.8)$ & $49(45.8)$ & $198(56.1)$ & $53(67.9)$ & \\
\hline II & $182(33.8)$ & $47(43.9)$ & $116(32.9)$ & $19(24.4)$ & \\
\hline III & $19(3.5)$ & $5(4.7)$ & $13(3.7)$ & $1(1.3)$ & \\
\hline IV & $13(2.4)$ & $1(0.9)$ & $10(2.8)$ & $2(2.6)$ & \\
\hline Transmitral gradient before the clip, $\mathrm{mmHg}$ & $1.68 \pm 1.25$ & $1.65 \pm 1.19$ & $1.65 \pm 1.30$ & $1.80 \pm 1.14$ & .799 \\
\hline Transmitral gradient after the clip, $\mathrm{mmHg}$ & $3.17 \pm 1.35$ & $3.39 \pm 1.17$ & $3.09 \pm 1.41$ & $3.23 \pm 1.13$ & .182 \\
\hline Urgent indication & $28(5.0)$ & $5(4.5)$ & $19(5.2)$ & $4(4.8)$ & .952 \\
\hline
\end{tabular}

DMR, degenerative mitral regurgitation; FMR, functional mitral regurgitation; MMR, mixed mitral regurgitation;

Values represent No. (\%) or mean \pm standard deviation.

Table 3

Intraprocedural and in-hospital complications

\begin{tabular}{|c|c|c|c|c|c|}
\hline & Total $(n=558)$ & $\operatorname{DMR}(\mathrm{n}=111)$ & FMR $(n=364)$ & $\operatorname{MMR}(n=83)$ & $P$ \\
\hline Clip detachment (partial or complete) & $10(1.8)$ & $4(3.6)^{*}$ & $4(1.1)$ & $2(2.4)$ & .232 \\
\hline Catheter thrombosis & $3(0.5)$ & 0 & $2(0.5)$ & $1(1.2)$ & .426 \\
\hline Subvalvular chordal rupture & $8(1.4)$ & $2(1.8)$ & $5(1.4)$ & $1(1.2)$ & .932 \\
\hline Clip entanglement in the subvalvular apparatus & $5(0.9)$ & $1(0.9)$ & $3(0.8)$ & $1(1.2)$ & .950 \\
\hline Puncture site hematoma & $24(4.3)$ & $8(7.2)$ & $15(4.1)$ & $1(1.2)$ & .100 \\
\hline Pseudoaneurysm & $9(1.6)$ & $2(1.8)$ & $6(1.6)$ & $1(1.2)$ & .941 \\
\hline Arteriovenous fistula & $4(0.7)$ & $1(0.9)$ & $1(0.3)$ & $2(2.4)$ & .181 \\
\hline Valvular surgery & $2(0.4)$ & $1(0.9)$ & $1(0.3)$ & 0 & .980 \\
\hline Hemorrhage (BARC criteria) & & & & & .142 \\
\hline 0 & $443(79.4)$ & $84(75.7)$ & $293(80.5)$ & $66(79.5)$ & \\
\hline 1 & $99(17.7)$ & $24(21.6)$ & $64(17.6)$ & $11(13.3)$ & \\
\hline 2 & $7(1.3)$ & $2(1.8)$ & $3(0.8)$ & $2(2.4)$ & \\
\hline $3 a$ & $7(1.3)$ & $1(0.9)$ & $2(0.5)$ & $4(4.8)$ & \\
\hline $3 b$ & $2(0.4)$ & 0 & $2(0.5)$ & 0 & \\
\hline Pericardial leak & $13(2.3)$ & $4(3.6)$ & $8(2.2)$ & $1(1.2)$ & .531 \\
\hline Death during hospital admission & $14(2.5)$ & 0 & $11(3.0)$ & $3(3.6)$ & .041 \\
\hline
\end{tabular}

BARC, Bleeding Academic Research Consortium; DMR, degenerative mitral regurgitation; FMR, functional mitral regurgitation; MMR, mixed mitral regurgitation; Data are expressed as No. (\%).

Only complete leaflet detachment.

ventricular ejection fraction $(P=.015)$. Follow-up was complete for $79.93 \%$ of the sample.

\section{Secondary endpoints}

Regarding the changes in the NYHA functional class (figure 2), there was a clear improvement at 3 months. This was maintained at 1 year, with $75.1 \%$ of the patients in NYHA I or II. This improvement was evident for all etiological groups of MR. The changes over time in the MR grade are shown in figure 3. There was a significant reduction in MR grade at 3 months, which was maintained at 12 months. At the end of follow-up, $73.2 \%$ of the patients had $\leq$ grade II MR. This improvement was found in all etiological groups of MR. 
A

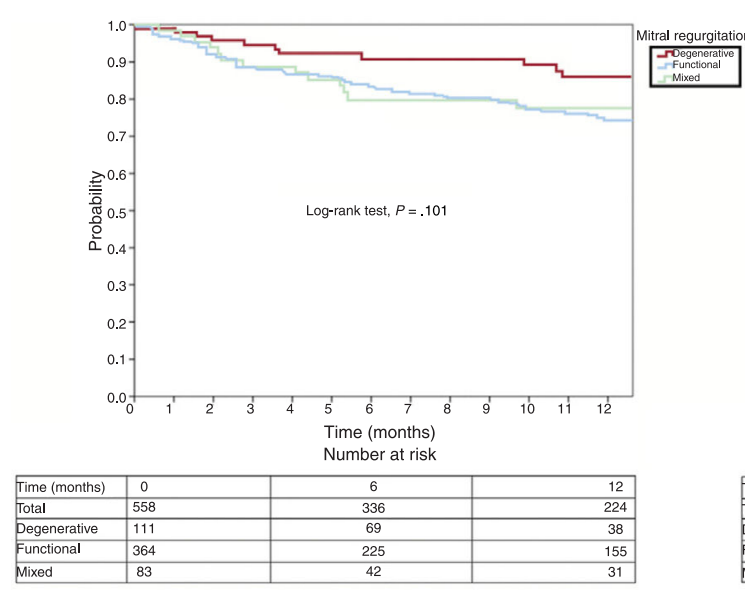

B

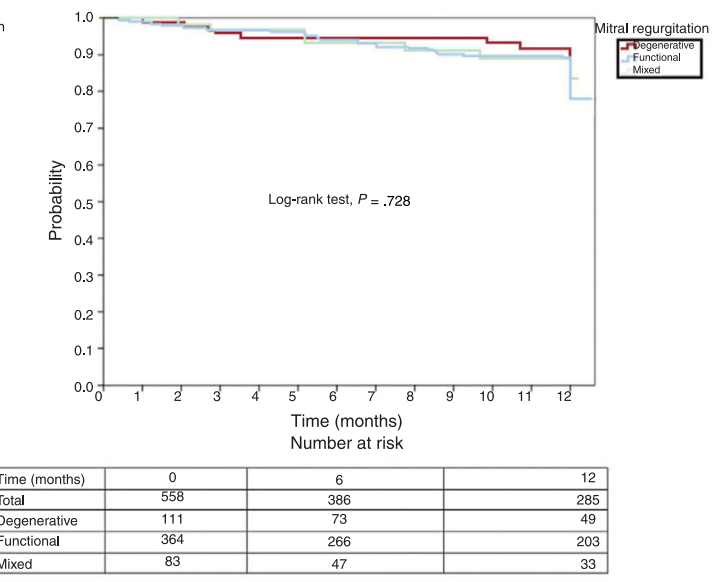

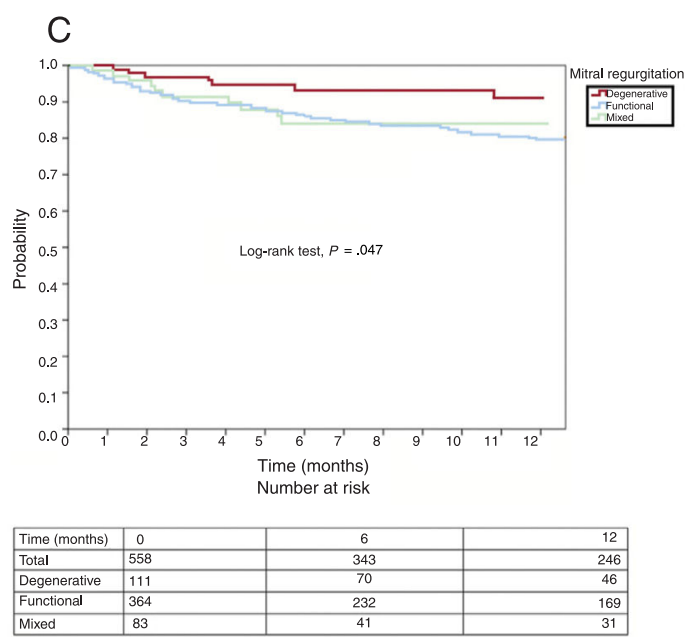

Figure 1. Twelve-month survival curves for the composite event (A), all-cause mortality (B), and readmission for heart failure (C) according to mitral regurgitation cause.

\section{DISCUSSION}

This collaborative project of 16 Spanish hospitals was performed in accordance with the recommendations of the Spanish Society of Cardiology regarding TMVR using a registry sponsored by this body and with real-life data from patients with symptomatic severe MR treated by TMVR with MitraClip.

Our series shows the safety and efficacy of TMVR with MitraClip in a high-risk population, with a persistent improvement in functional class and a reduction in MR grade. There were no significant differences in the primary study endpoint among the different MR types, although there was a trend toward a worse prognosis for FMR and MMR than for DMR.

In our series, the percentage of patients with FMR was higher than that of DMR. These data are in line with those published by other European registries (71\% in TRAMI, ${ }^{9} 77 \%$ in ACCES-EU, ${ }^{10} 76 \%$ in GRASP, ${ }^{11}$ and $72 \%$ in Sentinel ${ }^{12}$ ), reflecting the widespread use in Europe of this treatment for severe FMR (approximately 2-thirds with FMR vs 1-third with DMR). This contrasts with results from the United States, where TMVR has thus far been used predominantly for DMR. ${ }^{6-8}$
Our patients' clinical profile was similar to that reported in previous European series. The DMR group was older, whereas the FMR group had higher percentages of men, ischemic heart disease, percutaneous revascularization, and chronic obstructive pulmonary disease. ${ }^{9-12}$

We believe that it is important to highlight the high overall success of the procedure (94\%), which was similar for the different types of MR. The procedural success rate was higher than that published in the first trial (EVEREST $\mathrm{II}^{8}$ ) but comparable to the results of other registries $\left(97 \%,{ }^{9} 91 \%,{ }^{10} 100 \%,{ }^{11}\right.$ and $95 \%{ }^{12}$ ). Together with the low rate of major procedure-related complications, this success rate reflects the applicability of the previous evidence to our setting. ${ }^{9-12}$ The accumulation of greater experience by the teams performing the procedure has been key to the improved results.

In our series, there were no significant differences in the number of clips implanted according to MR type. In previous series, a higher number of clips were indicated for the treatment of DMR with larger regurgitant volumes, although adequate treatment has also been documented of severe MR with a single clip. ${ }^{16}$ Proper patient selection is essential to correctly determine the number of clips to use. ${ }^{17,18}$ 
Table 4

Univariable analysis of the primary study endpoint (death or readmission at 12 months)

\begin{tabular}{|c|c|c|c|}
\hline & HR & $95 \% \mathrm{CI}$ & $P$ \\
\hline Mitral regurgitation cause & & & .110 \\
\hline DMR & 1 & - & \\
\hline FMR & 1.977 & $1.047-3.730$ & .036 \\
\hline MMR & 1.793 & $0.803-4.002$ & .154 \\
\hline Age, $y$ & 0.987 & $0.971-1.003$ & .113 \\
\hline Male sex & 0.932 & $0.601-1.444$ & .751 \\
\hline$B M I$ & 0.992 & $0.950-1.036$ & .721 \\
\hline NT device implantation (NT vs another) & 0.682 & $0.412-1.130$ & .682 \\
\hline NYHA functional class (II vs III/IV) & 1.500 & $1.056-2.131$ & .024 \\
\hline Cardiac surgery & 1.372 & $0.853-2.206$ & 1.192 \\
\hline Ischemic heart disease & 1.057 & $0.711-1.571$ & .784 \\
\hline Myocardial infarction & 0.373 & $0.092-1.513$ & .167 \\
\hline Surgical revascularization & 2.285 & $0.928-5.626$ & .072 \\
\hline Percutaneous revascularization & 1.104 & $0.730-1.668$ & 640 \\
\hline EUROSCORE II & 1.030 & $1.011-1.049$ & .002 \\
\hline STS score & 1.019 & 0.989-1.049 & .212 \\
\hline COPD & 1.395 & $0.886-2.198$ & .151 \\
\hline Stroke & 0.686 & $0.279-1.688$ & .413 \\
\hline Severe pulmonary hypertension $(\geq 60 \mathrm{mmHg}$ ) & 0.923 & $0.573-1.487$ & .741 \\
\hline Type 2 diabetes mellitus & 1.744 & $1.171-2.597$ & .006 \\
\hline Hypertension & 0.897 & $0.590-1.363$ & 610 \\
\hline Smoker & 1.274 & $0.798-2.033$ & .310 \\
\hline Hypercholesterolemia & 0.967 & $0.650-1.439$ & .868 \\
\hline Previous renal failure (creatinine $>2.5 \mathrm{~g} / \mathrm{dL}$ ) & 1.111 & $0.486-2.544$ & .803 \\
\hline Creatinine & 1.114 & $0.885-1.403$ & .359 \\
\hline Atrial fibrillation & 0.885 & $0.595-1.315$ & .545 \\
\hline LVEF & 0.975 & $0.961-0.991$ & .002 \\
\hline LVEF $<30 \%$ & 1.533 & $1.010-2.326$ & .045 \\
\hline Hemodialysis & 1.756 & $0.645-4.780$ & .270 \\
\hline Inotropic agents & 1.661 & $0.985-2.803$ & .057 \\
\hline Number of clips & 0.764 & $0.551-1.059$ & .107 \\
\hline
\end{tabular}

95\%CI, 95\% confidence interval; BMI, body mass index; COPD, chronic obstructive pulmonary disease; DMR, degenerative mitral regurgitation; FMR, functional mitral regurgitation; HR, hazard ratio; LVEF, left ventricular ejection fraction; MMR, mixed mitral regurgitation; NYHA, New York Heart Association; STS, Society of Thoracic Surgeons.

The MR reduction after implantation in our series was significant for both DMR and FMR, in line with the results of the main clinical trials ${ }^{7,13,14}$ and international registries. ${ }^{9-12}$ Our data show that the MR reduction is maintained at $\leq$ grade II in $73.2 \%$ of patients at 12 months. This percentage is consistent with that reported in the first European registry ${ }^{10}$ and in more recent ones. ${ }^{11}$

The composite event-free survival of the entire series was $77.1 \%$, with no significant differences $(P=.101)$ among the different groups: $85.8 \%$ for DMR, $74.5 \%$ for FMR, and $77.7 \%$ for MMR.

The absence of differences between the DMR and FMR groups for this composite endpoint was also reported by Nickenig et al. ${ }^{12}$ and, as in our series, they found a tendency for worse prognosis with FMR. In our work, the primary outcome event rate was higher in the FMR group (21.3\%) than in the DMR group (11.3\%). This result should be interpreted in the context of the sample size and the length of follow-up in this study; larger studies with a longer follow-up might find significant differences.
Table 5

Multivariable analysis of the primary study endpoint (death or readmission at 12 months)

\begin{tabular}{llll}
\hline & HR & $95 \% \mathrm{CI}$ & $P$ \\
\hline NYHA functional class (class II vs III/IV) & 3.641 & $1.143-11.601$ & .029 \\
\hline Previous surgical revascularization & 2.720 & $1.098-6.742$ & .031 \\
\hline EuroSCORE II & 1.030 & $1.010-1.050$ & .003 \\
\hline Type 2 diabetes mellitus & 1.560 & $1.027-2.369$ & .037 \\
\hline Left ventricular ejection fraction & 0.981 & $0.967-0.996$ & .015
\end{tabular}

95\%CI, 95\% confidence interval; HR, hazard ratio; NYHA, New York Heart Association.

This trend could be explained by the presence of a higher risk profile in the FMR group than in the DMR group (ie, more comorbidities and worse left ventricular ejection fraction). Although there was a certain tendency for worse prognosis in the FMR and MMR groups vs the DMR group, there was no significant difference in the composite endpoint.

The all-cause mortality at 1 year of follow-up in our series is very similar to that of some recent European registries $\left(15.3 \%^{12}\right.$ and $14.4 \%{ }^{11}$ ) and somewhat lower than that of others from the same region $\left(19.2 \%^{10}\right.$ and $\left.20.3 \%^{9}\right)$, probably due to the different clinical characteristics of the patients included.

Our data are in line with the findings of a recent meta-analysis that identified an overall all-cause mortality rate of $16 \%$, with no difference between DMR and FMR (HR =1.26; 95\%CI, 0.90-1.77; $P=.18$ ). This work also showed the tendency of the FMR group to have a worse prognosis and a higher percentage of admissions for HF. ${ }^{19}$

According to MR cause, all-cause mortality per year was $11.7 \%$ in the DMR group of our series. This figure is slightly higher than that reported in the EVEREST II trial ${ }^{7}$ because it included low-risk patients who were surgical candidates.

Regarding FMR, all-cause mortality at 1 year was $15.7 \%$ in our series. This rate is lower than that published recently in the 2 main clinical trials comparing TMVR with medical therapy alone. One of the possible explanations for this difference is the higher risk characteristics of the patients included in these studies. In the COAPT trial, ${ }^{13}$ the mean Society of Thoracic Surgeons (STS) score was $7.8 \%$ in the MitraClip group, with more than $40 \%$ of the patients in this group having an STS $\geq 8$, whereas the median was 3.3 in the FMR group in our series. Similarly, the average EuroSCORE II in the MitraClip group was 6.6 in the MITRA-FR trial, ${ }^{14}$ but 4.4 in the FMR group in our series.

This work presents the data related to MitraClip treatment; however, there are other percutaneous mitral repair devices on the market with less accumulated experience, that act on different therapeutic targets of the mitral valve apparatus, and that can even complement the treatment with this MitraClip.

\section{Limitations}

This work has some limitations. The number of patients comprising this series is small and the follow-up is not particularly long. Because this is an observational study, there is no evidence that it has sufficient power to detect significant differences in the primary endpoint; in addition, the different distributions of some variables among the 3 groups could introduce biases during followup. The classification of some patients as having MMR is controversial and this approach could represent the loss of a 


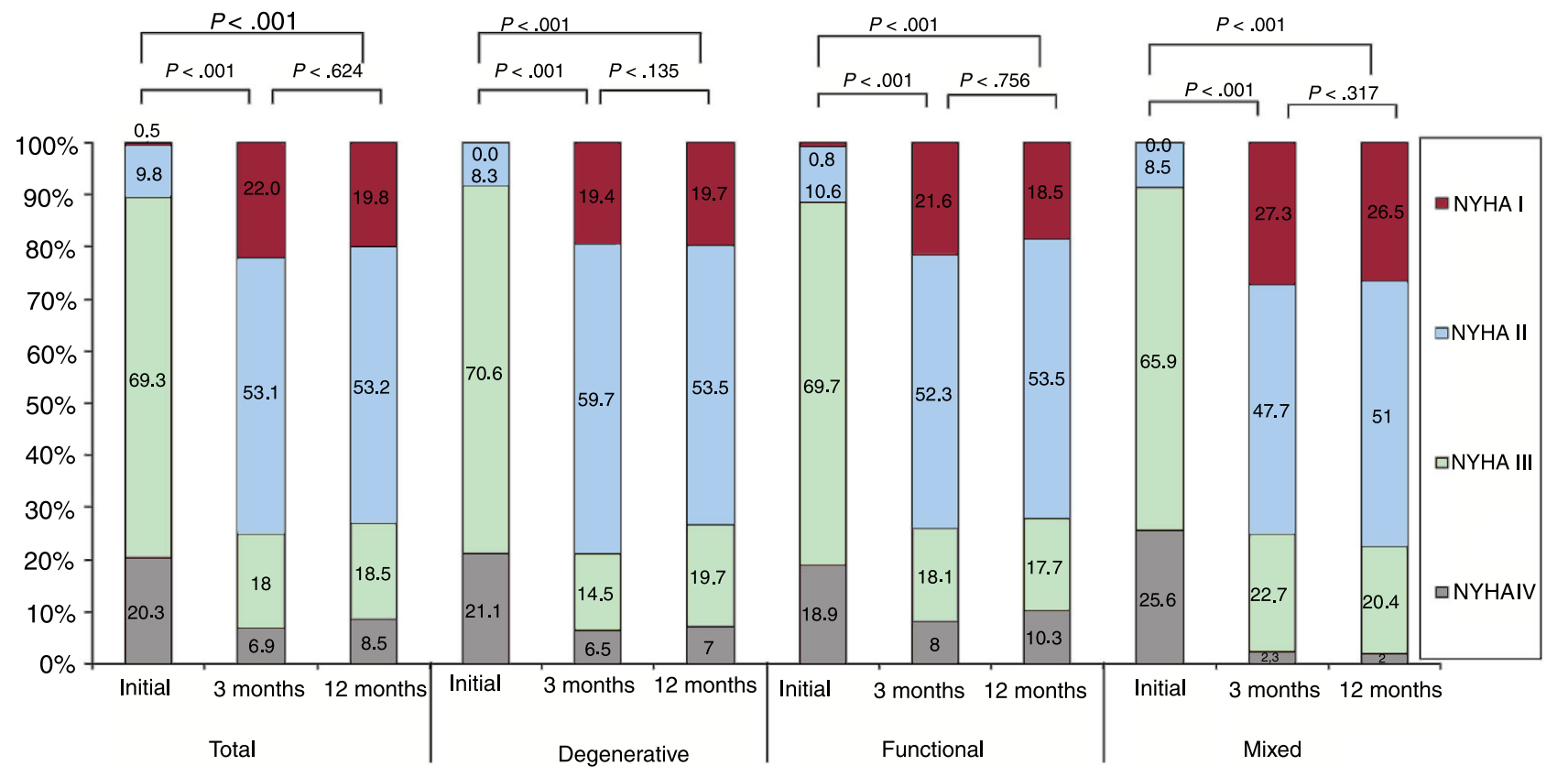

Figure 2. Changes over time in NYHA functional class during follow-up in the entire series and according to mitral regurgitation cause. NYHA, New York Heart Association.

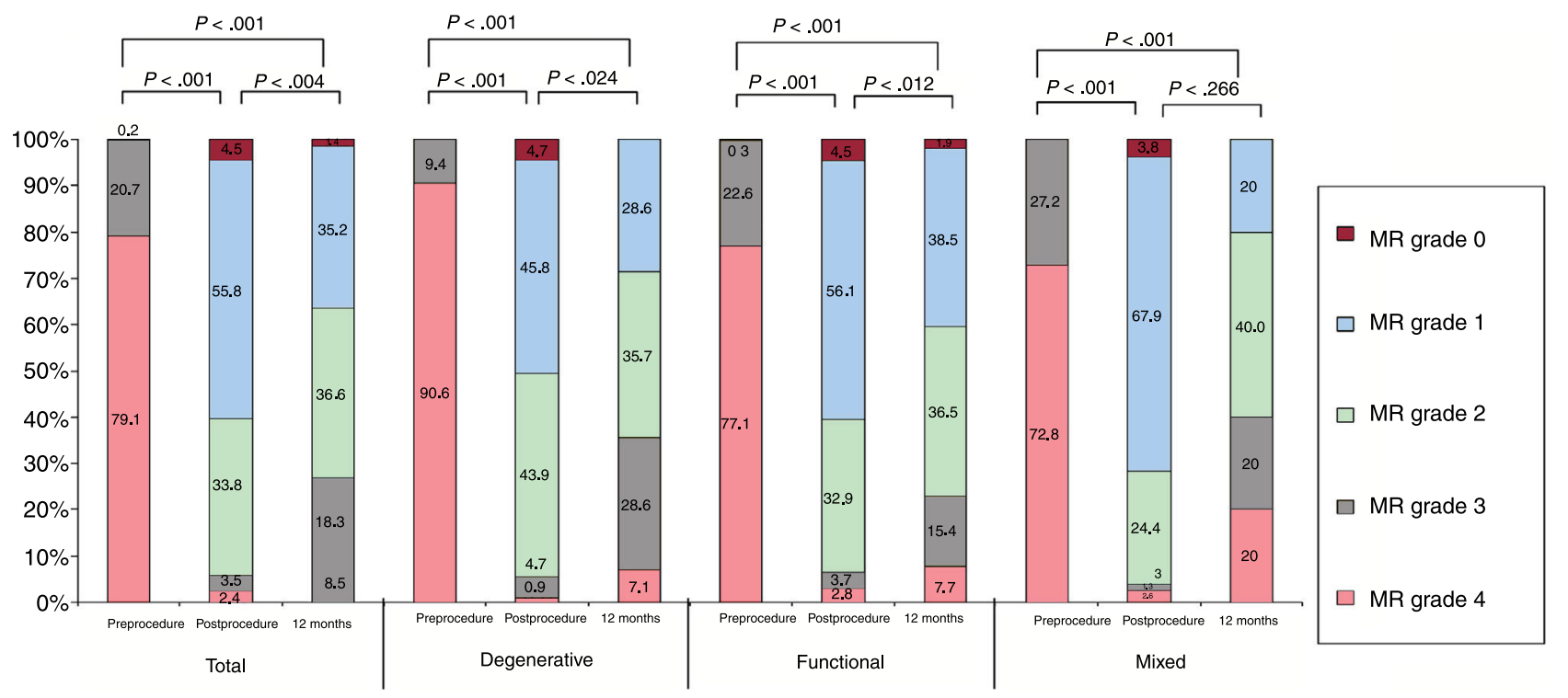

Figure 3. Changes over time in MR grade during follow-up in the entire series and according to MR cause. MR, mitral regurgitation.

percentage, albeit small, of patients from the other 2 subgroups. Finally, another limitation may be the absence of a centralized imaging laboratory.

\section{CONCLUSIONS}

This is the largest reported series of patients with MR treated by TMVR in Spain and reflects the general use of the technique in our environment. This work confirms, through real-life data from Spain, the safety and efficacy of the treatment and documents the main factors associated with prognosis during the first year of follow-up of these patients.

\section{CONFLICTS OF INTEREST}

None declared. 


\section{WHAT IS KNOWN ABOUT THE TOPIC?}

- TMVR with the MitraClip device is safe and effective for both degenerative and functional MR. No significant differences have been found in the prognosis of patients treated with TMVR according to MR cause.

\section{WHAT DOES THIS STUDY ADD?}

- This article contributes to a better understanding of the setting of severe and symptomatic MR treated by TMVR according to cause. This work confirms the safety and efficacy of the treatment in Spain and documents the main factors associated with prognosis during the first year of follow-up of these patients.

\section{REFERENCES}

1. Nkomo VT, Gardin JM, Skelton TN, Gottdiener JS, Scott CG, Enriquez-Sarano M. Burden of valvular heart diseases: a population-based study. Lancet. 2006;368:1005-1011.

2. Trichon BH, Felker GM, Shaw LK, Cabell CH, O'Connor CM. Relation of frequency and severity of mitral regurgitation to survival among patients with left ventricular systolic dysfunction and heart failure. Am J Cardiol. 2003;91:538-543.

3. Zoghbi WA, Adams D, Bonow RO, et al. Recommendations for noninvasive evaluation of native valvular regurgitation: a report from the American Society of Echocardiography Developed in Collaboration with the Society for Cardiovascular Magnetic Resonance. J Am Soc Echocardiogr. 2017;30:303-371.

4. Baumgartner H, Falk V, Bax JJ, et al. 2017 ESC/EACTS Guidelines for the management of valvular heart disease. Eur Heart J. 2017;38:2739-2791.

5. Nishimura RA, Otto CM, Bonow RO, et al. 2017 AHA/ACC Focused Update of the 2014 AHA/ACC Guideline for the Management of Patients With Valvular Heart
Disease: A Report of the American College of Cardiology/American Heart Association Task Force on Clinical Practice Guidelines. J Am Coll Cardiol. 2017:70:252-289.

6. Feldman T, Foster E, Glower DD, et al. Percutaneous repair or surgery for mitral regurgitation. N Engl J Med. 2011;364:1395-1406.

7. Glower DD, Kar S, Trento A, et al. Percutaneous mitral valve repair for mitral regurgitation in high-risk patients: results of the EVEREST II study. J Am Coll Cardiol. 2014;64:172-181.

8. Feldman T, Kar S, Elmariah S, et al. Randomized comparison of percutaneous repair and surgery for mitral regurgitation: 5-year results of EVEREST II. J Am Coll Cardiol. 2015;66:2844-2854

9. Baldus S, Schillinger W, Franzen O, et al. MitraClip therapy in daily clinical practice: initial results from the German transcatheter mitral valve interventions (TRAMI) registry. Eur J Heart Fail. 2012;14:1050-1055.

10. Maisano F, Franzen O, Baldus S, et al. Percutaneous mitral valve interventions in the real world: early and 1-year results from the ACCESS-EU, a prospective, multicenter, nonrandomized post-approval study of the MitraClip therapy in Europe. J Am Coll Cardiol. 2013;62:1052-1061.

11. Grasso C, Capodanno D, Scandura S, et al. One- and twelve-month safety and efficacy outcomes of patients undergoing edge-to-edge percutaneous mitral valve repair (from the GRASP Registry). Am J Cardiol. 2013;111:1482-1487.

12. Nickenig G, Estevez-Loureiro R, Franzen O, et al. Percutaneous mitral valve edgeto-edge repair: in-hospital results and 1-year follow-up of 628 patients of the 2011-2012 Pilot European Sentinel Registry. J Am Coll Cardiol. 2014:64:875-884.

13. Stone GW, Lindenfeld J, Abraham WT, et al. Transcatheter mitral-valve repair in patients with heart failure. N Engl J Med. 2018;379:2307-2318.

14. Obadia JF, Messika-Zeitoun D, Leurent G, et al. Percutaneous repair or medical treatment for secondary mitral regurgitation. N Engl J Med. 2018;379:2297-2306.

15. Mehran R, Rao SV, Bhatt DL, et al. Standardized bleeding definitions for cardiovascular clinical trials: A consensus report from the Bleeding Academic Research Consortium. Circulation. 2011:123:2736-2747.

16. Franzen O, van der Heyden J, Baldus S, et al. MitraClip therapy in patients with endstage systolic heart failure. Eur J Heart Fail. 2011;13:569-576.

17. Paranskaya L, D’Ancona G, Bozdag-Turan I, et al. Percutaneous mitral valve repair with the MitraClip system: perioperative and 1-year follow-up results using standard or multiple clipping strategy. Catheter Cardiovasc Interv. 2013;81:1224-1231.

18. Buzzatti N, Denti P, Scarfò IS, et al. Mid-term outcomes (up to 5 years) of percutaneous edge-to-edge mitral repair in the real-world according to regurgitation mechanism: A single-center experience. Catheter Cardiovasc Interv. 2018. http://dx.doi.org/10.1002/ccd.28029.

19. Chiarito M, Pagnesi M, Martino EA, et al. Outcome after percutaneous edge-to-edge mitral repair for functional and degenerative mitral regurgitation: a systematic review and meta-analysis. Heart. 2018;104:306-312. 